\title{
Outpatient visit among elderly in Indonesia
}

\author{
Haerawati Idris, Nurafni \\ Department of Health Policy and Administration, Faculty of Public Health, Sriwijaya University, Indonesia
}

\begin{tabular}{l}
\hline Article Info \\
\hline Article history: \\
Received Feb 4, 2021 \\
Revised Aug 17, 2021 \\
Accepted Aug 26, 2021 \\
\hline
\end{tabular}

\section{Keywords:}

Elderly

Health service

Indonesia family life survey

Outpatient

Utilization

\begin{abstract}
Population aging has become an important issue mostly discussed in many countries in the world. The proportion of the older population is getting better in both developed and developing countries. Elderly tend to need more health care as they are more susceptible to chronic diseases. The purpose of this study was to determine the factors affecting outpatient visit among elderly in Indonesia. This study employed a cross-sectional study design with a sample of $\geq 60$-year-old individual with a total sample of 5,325 elderly. The data used to be analyzed were from the Indonesian Family Life Survey 2014 representing $83 \%$ of the population in Indonesia. The theory used was Andersen health service utilization model. In analyzing the data, bivariate analysis were used, with Chi-square and multivariate test using multiple logistic regression test prediction model. Elderly who utilize health service for outpatient was $18.6 \%$. Variables that have significant relationships with outpatient utilization on elderly were female, high education, formal job, Java and Bali, urban, health insurance ownership, economic status, the perception of ill, smoking habit, history of chronic disease, fat, and obesity. Predictor for the most dominant outpatient utilization is influenced by chronic disesase after controlled by other variables. Chronic disesase greatly affect the elderly in utilizing health services for outpatient. To overcome this, the government is expected to provide policies on health facilities to better emphasize promotive and preventive efforts among the elderly.
\end{abstract}

This is an open access article under the CC BY-SA license.

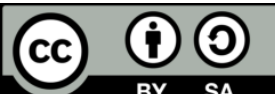

\section{Corresponding Author:}

Haerawati Idris

Department of Health Policy and Administration

Faculty of Public Health

Sriwijaya University

Jl. Raya Palembang-Unsri KM 32 Indralaya, Ogan Ilir, South Sumatera, Indonesia

Email: haera@fkm.unsri.ac.id

\section{INTRODUCTION}

The population of the elderly becomes a very important issue mostly discussed in some parts of the world. It is estimated that in $2050,79 \%$ of the elderly are in developing areas [1]. Indonesia itself has about $8.04 \%$ elderly and their morbidity rate is around $28.62 \%$, sick elderly utilizing health service for outpatient are $72.16 \%$ [2]. Age is very important to the utilization of health services, the older the person, the higher the health services utilization will be [3]. The prevalence of multi-morbidity increases with age and substantial among older adults [4], [5]. Several studies related to factors affecting the elderly utilizing health care services. Educational level, marital status, health insurance ownership, reports of chronic diseases, and nutritional status are influencing the utilization of health services [6]-[9].

Age influences individuals to take advantage of health services. The elderly have a higher risk of chronic disease than the younger individuals, so the utilization of health service seems different to the youngers. Elderly who have comorbid diseases do not take advantage of health services will have poor health 
status. The study related to the elder's outpatient utilization in Indonesia is still limited. It is very important for health care policy on elderly groups. The purpose of this study was to analyze the factors influencing the utilization of outpatient among elderly.

\section{RESEARCH METHOD}

\subsection{Design study}

This study employed a cross-sectional study design. The Indonesia Family Life Survey 2014 data wa used in this research. IFLS is a survey that aims to provide a depiction of health and socio-economic household's conditions in Indonesia done in a sustainable manner. Indonesian Family Life Survey (IFLS) is a sustainable socio-economic and health survey.

\subsection{Sample}

There were 5,325 elderly were obtained as the sample. The dependent variable in this study is outpatient visits. Outpatient visit use was scored 'yes' if the individual reported having visited a public hospital, public health center (Puskesmas), private hospital, clinic, health worker, or doctor's practice or had been visited by a health worker or doctor for outpatient care in the past 4 weeks. The variable was scored 'no' if this was not the case. Variables were established based on information on outpatient visits during the last month before the survey was conducted. We used data from The Indonesia Family Life Survey (IFLS). The first wave (IFLS 1) was administered in 1993. IFLS 2 sought to reinterview the same respondents four years later. The next wave, IFLS 3, was fielded on the full sample in 2000. IFLS 4 was fielded in late 2007. IFLS 5 was fielded in late 2014. We used data (The fifth wave) for this study. This survey carried out by a team from the RAND corporation collaborated with Indonesian researchers. The RAND Corporation is a nonprofit institution that helps improve policy and decisionmaking through research and analysis. The sample of this survey consisted of individuals aged 15-65 years. The data survey used multistage stratified sampling design. The survey is based on a sample of households representing about $83 \%$ of the Indonesian population living in 13 of 27 provinces. The survey collects data about individuals, their families and households, the communities where they live in, health and education facilities that they use. The sampling used on IFLS was multistage random sampling [10].

\subsection{Variable}

Independent variables in this study were gender, education, marital status, occupation, region, area location, health insurance ownership, and economic status, history of chronic disease, health perception, smoking habit, nutritional status, and physical activity. The analysis in this study used bivariate with Chisquare and multivariate with multiple logistic regression prediction models. The analysis was completed using the statistical package STATA 12.0 SE. The variables were summarized with descriptive statistics (N, percentages).

\section{RESULTS AND DISCUSSION}

\subsection{Univariate}

Elderly who utilize health services for outpatient care $(18.6 \%)$ and those who did not are $(81.4 \%)$. Majority of the elderly who have low education are (79.6\%), married are (70.9\%), work in informal sector are $(87.5 \%)$, live in Java and Bali are $(66.0 \%)$. Those who live in rural area are $(52.4 \%)$, do not have health insurance are $(56.8 \%)$, have very poor economic status are $(27.7 \%)$. Hence, those who have no history of chronic diseases are $(90.1 \%)$, have an ill health status are $(66.5 \%)$, have smoking habit are $(51.7 \%)$, have normal nutritional status are $(44.4 \%)$ and have low physical activity are $(85.2 \%)$.

\subsection{Bivariate analysis}

Table 1 shows the elderly who utilize outpatient majority are women, have midle education, work in formal job, live in Java and Bali area, live in urban area, have health insurance, have middle to very rich economic status, have history of chronic disease, have perception of healthy, have no smoking habit and are obese. Based on the results of cross-tabulation analysis of variables that have significant relationship with the utilization of outpatient on elderly are gender, education (high), occupation, region (Java and Bali), location of area, health insurance, economic status, history of chronic disease, smoking habits, poor self reported and nutritional status.

\subsection{Multivariate analysis}

Table 2 shows the factors affecting outpatient utilization in the elderly. The results of health service utilization for outpatients on elderly shows that respondents who have middle education have a greater 
probability of utilizing outpatient care than the respondent who has low education. The respondent who stay in Sumatera have a greater probability of utilizing outpatient care than respondents who stay in the East region. The probability of elderly utilizing outpatient increases with the ownership of health insurance. Health insurance has a significant relationship with outpatient utilization for the elderly.

Household income significantly affects the outpatient utilization of the elderly. The probability of outpatient utilization is increasing with increasing household income. The history of chronic diseases significantly affects the use of outpatients. The elderly who have a history of chronic diseases have a greater risk than the elderly who do not have the chronic disease to take advantage of outpatient care. Self-reported significantly affect the outpatient utilization of the elderly. Elderly who have poor self-reported to utilize outpatient care are smaller than those with good self-reported. Smoking elderly have a smaller probability of taking outpatient than non-smokers. Chronic disease is the most dominant variable influencing outpatient visit among elderly in healthcare facility (p-value <0.001; OR 1.972; 95\% CI 1.600-2.492).

Table 1. Bivariate analysis of outpatient visit

\begin{tabular}{|c|c|c|c|c|c|}
\hline \multirow{2}{*}{ Variables } & \multicolumn{2}{|c|}{ Outpatient } & \multirow{2}{*}{$\operatorname{Pr}$} & \multicolumn{2}{|c|}{$95 \% \mathrm{ci}$} \\
\hline & Yes $\%$ & No $\%$ & & Lower & Upper \\
\hline \multicolumn{6}{|l|}{ Gender } \\
\hline Female & 21.0 & 79.0 & $1.24 * * *$ & 1.11 & 1.39 \\
\hline Male & 16.9 & 83.1 & 1 & & \\
\hline \multicolumn{6}{|l|}{ Education } \\
\hline Low & 17.7 & 82.3 & 1 & & \\
\hline Middle & 20.3 & 79.7 & 1.19 & 0.99 & 1.42 \\
\hline High & 32.3 & 67.7 & $2.22 * * *$ & 1.61 & 3.04 \\
\hline \multicolumn{6}{|c|}{ Marital status } \\
\hline Married & 18.4 & 81.6 & 0.96 & 0.85 & 1.08 \\
\hline Others & 19.2 & 80.8 & 1 & & \\
\hline \multicolumn{6}{|l|}{ Job } \\
\hline Formal & 23.1 & 76.9 & $1.3 * *$ & 1.1 & 1.49 \\
\hline Informal & 18 & 82 & 1 & & \\
\hline \multicolumn{6}{|l|}{ Region } \\
\hline Sumatera & 17.9 & 82.1 & 1.16 & 0.9 & 1.48 \\
\hline Java and Bali & 19.5 & 80.5 & $1.28 *$ & 1.04 & 1.57 \\
\hline Eastern part & 15.9 & 81.4 & 1 & & \\
\hline \multicolumn{6}{|l|}{ Area socation } \\
\hline Urban & 20 & 80 & $1.15^{*}$ & 1.03 & 1.28 \\
\hline Rural & 17.4 & 82.6 & & 1 & \\
\hline \multicolumn{6}{|c|}{ Health insurance ownership } \\
\hline Yes & 21.9 & 78.1 & $1.36 * * *$ & 1.21 & 1.52 \\
\hline No & 16.2 & 83.8 & 1 & & \\
\hline \multicolumn{6}{|c|}{ Economic status } \\
\hline Very poor & 14.5 & 85.5 & 1 & & \\
\hline Poor & 19.6 & 80.4 & $1.45^{* * *}$ & 1.18 & 1.78 \\
\hline Middle & 20.2 & 79.8 & $1.49 * * *$ & 1.21 & 1.85 \\
\hline Rich & 19.9 & 80.1 & $1.47 * * *$ & 1.18 & 1.84 \\
\hline Very rich & 21.4 & 78.6 & $1.61 * * *$ & 1.30 & 2.00 \\
\hline \multicolumn{6}{|c|}{ History of chronic disease } \\
\hline Yes & 35.4 & 64.6 & $2.11 * * *$ & 1.85 & 2.4 \\
\hline No & 16.8 & 83.2 & & 1 & \\
\hline \multicolumn{6}{|l|}{ Self-reported } \\
\hline Poor & 13.4 & 86.6 & $0.46^{* * *}$ & 0.41 & 0.51 \\
\hline Good & 29.1 & 70.9 & & & \\
\hline \multicolumn{6}{|c|}{ Smoking habit } \\
\hline Yes & 16.1 & 83.9 & $0.76^{* * *}$ & 0.68 & 0.85 \\
\hline No & 21.3 & 78.7 & 1 & & \\
\hline \multicolumn{6}{|c|}{ Nutritional status } \\
\hline Lean & 17.1 & 82.9 & 1,03 & 0.85 & 1.26 \\
\hline Normal & 16.6 & 83.4 & 1 & & \\
\hline Fatty & 19.9 & 80.1 & $1.24 *$ & 1.01 & 1.52 \\
\hline Obese & 23.3 & 76.7 & $1.52 * * *$ & 1.28 & 1.81 \\
\hline \multicolumn{6}{|c|}{ Physical activities } \\
\hline Less active & 18.8 & 81.2 & 1.01 & 0.79 & 1.28 \\
\hline Normal & 17.1 & 82.9 & 0.97 & 0.62 & 1.32 \\
\hline Very active & 18.6 & 81.4 & 1 & & \\
\hline
\end{tabular}

Int. J. Public Health Sci., Vol. 10, No. 4, December 2021 : 913 - 919 
Table 2. Final model of multivariate analysis used logistic regression

\begin{tabular}{|c|c|c|c|c|}
\hline \multirow{2}{*}{ variables } & \multirow{2}{*}{ Sig. } & \multirow{2}{*}{$\operatorname{Exp}(B)$} & \multicolumn{2}{|c|}{$95 \%$ C.I } \\
\hline & & & Lower & Upper \\
\hline \multicolumn{5}{|l|}{ Education (low) } \\
\hline Midle & 0.006 & 1.369 & 1.154 & 2.328 \\
\hline High & 0.604 & 1.053 & 0.866 & 1.280 \\
\hline \multicolumn{5}{|c|}{ Region (east region) } \\
\hline Sumatera & 0.006 & 1.353 & 1.089 & 1.061 \\
\hline Java and Bali & 0.661 & 1.060 & 0.817 & 1.376 \\
\hline \multicolumn{5}{|c|}{ Employee (informal) } \\
\hline Formal & 0.063 & 1.216 & 0,990 & 1.494 \\
\hline \multicolumn{5}{|l|}{ Insurance (no) } \\
\hline Yes & 0.001 & 1.289 & 1.111 & 1.5494 \\
\hline \multicolumn{5}{|c|}{ Household income (poorest) } \\
\hline Poor & 0.007 & 1.332 & 1.062 & 1.670 \\
\hline Middle & 0.000 & 1.517 & 1,217 & 1.892 \\
\hline Rich & 0.039 & 1.283 & 1.013 & 1.626 \\
\hline Very rich & 0.034 & 1.292 & 1.019 & 1.638 \\
\hline \multicolumn{5}{|c|}{ Chronic disease (no) } \\
\hline Yes & 0.000 & 1.972 & 1.600 & 2.492 \\
\hline \multicolumn{5}{|c|}{ Self-reported (good) } \\
\hline Poor & 0.000 & 0.383 & 0.331 & 0.444 \\
\hline \multicolumn{5}{|l|}{ Smoker (no) } \\
\hline Yes & 0.000 & 0.741 & 0.645 & 0.868 \\
\hline \multicolumn{5}{|c|}{ Nutrition status (normal) } \\
\hline Lean & 0.297 & 1.118 & 0.908 & 1.371 \\
\hline Fatty & 0.133 & 1.176 & 0.952 & 1.452 \\
\hline Obesity & 0.044 & 1.214 & 1.006 & 1.467 \\
\hline
\end{tabular}

\subsection{Discussion}

This paper aimed to determine the factors that influence the utilization of outpatient on the elderly. Outpatient utilization on the elderly is $18.6 \%$, outpatient utilization increased with age [3]. The fact that more and more people are reaching old age has resulted in changes in patterns of illness such as chronic conditions [11]. Outpatient utilization on elderly is dominated by women who have secondary education, work in the formal sector, live in Java and Bali, live urban areas, have health insurance, have a high income, have a history of chronic diseases, have healthy perception, have no smoking habit and are obese. Health care utilisation is also associated with environmental determinants such as the availability and accessibility of services, which can vary geographically. Health service facilities outside Java and Bali are still limited than Java and Bali. Based on the results of the analysis, the elderly who have higher education have a greater risk of utilizing outpatient care. This study is consistent with Chen [12]. Higher the level of education will influence the mindset in making decisions to do utilizing health care when needed [12]-[14].

The regional differences in the elderly can also affect the utilization of outpatient; this can be caused by each region having different government policies, trust, endemic in diseases and population density. elderly working in the formal sector has a greater probability of using outpatients. Working in the informal sector such as farmers tends to have lower incomes [8].

Elderly who have health insurance have a greater probability of utilizing outpatient care. The results of this study are in line with other studies [15], [16]. Not covered by health insurance and having a high economic burden will largely delay the utilization of outpatient care when needing it [12]. Income will affect the decision of the elderly to utilize outpatient services or not. The results of this study show that outpatient utilization is influenced by household income. Compared to the elderly who have very poor income, all elderly have a greater risk of taking outpatient care. The higher the economic status is, the better the health status will be [15]. The risk of disease infection is higher on people with low economic status [8].

This study found that the elderly with chronic disease have a probability of 1.97 times to have an outpatient visit in a healthcare facility. A history of chronic disease will affect the decision of the elderly to utilize outpatient services. Elderly who have a history of chronic disease have a greater risk of taking outpatient care after being controlled by other variables. This study is in line with other studies [14], [17], [18]. The older a person is, the higher the risk for infected diseases, especially chronic disease [19], [20]. The presence of chronic diseases can limit daily activities [11]. Thus, it can encourage someone to do one treatment using outpatient [8]. Self-reported is a predictor in influencing elderly utilizing outpatient care. During the interview, the elderly having poor self-reported having a smaller probability of utilizing outpatient care. It can be understood that when a person's health status is good then good health utilization will be depicted [21]. This study is in line with other studies finding that health perception has a significant relationship with outpatient utilization [14], [22]. 
Smoking habits affect the elderly utilizing outpatient. Based on the results of this study, elderly who have a smoking habit have a smaller risk to take care of outpatient. The results of this study are in line with other studies [13]. During the interview, the elderly who have lived a long life and do not have a smoking habit are likely to have quit smoking because they have felt the consequences of it [23]. Elderly people who have obesity nutritional status have a greater probability of utilizing outpatient care. Obesity is a risk factor for various chronic diseases [7], [24]. Such as cardiovascular diseases [25], stroke, cancer, diabetes, hearth diseases [19], [20] so this will have an impact on the utilization of health services.

This study has some limitations that need to be discussed. First, this study used secondary data, so it only explored the available variables in the dataset. Several variables, such as waiting time [26], mental health status [27], local insurance [28], and activities of daily living, regular medication [29] and ethnicity [30] were not included in this study due to data limitations. Second, this study used a cross-sectional study design, so it is possible to have information bias when requesting data. Furthermore, this research design can only see the relationship between the variables studied without being able to see a causal relationship among them. The study also asks self-reported, and elderly may have difficulties in memorizing their health services utilization for once week. Recall bias could not be ruled out.

\section{CONCLUSION}

Chronic disesase is a predictor of outpatient utilization among elderly. To overcome this, the government is expected to provide policies on health facilities to better emphasize promotive and preventive. Health promotion for the elderly about the importance of healthy living at their age is needed. For the elderly in Indonesia, they are expected to apply a healthy lifestyle at their age.

\section{REFERENCES}

[1] World Health Organization, "World Population Ageing," World Health Organization, 2017, [Online]. Available: https://www.un.org/en/development/desa/population/publications/pdf/ageing/WPA2017_Highlights.pdf.

[2] Statistics Indonesia, "Statistik, Elderly population," Statistics Indonesia, 2015, [Online]: Available: https://www.bps.go.id/publication/2016/11/07/f9d00ad72285396ecb1801dc/statistik-penduduk-lanjut-usia2015.html.

[3] B. Babitsch, G. Daniela, and T. Von, "Re-revisiting Andersen's Behavioral Model of Health Services Use : a systematic review of studies from 1998-2011," GMS Psycho-Social-Medicine, vol. 9, pp. 1-15, 2012, doi: $10.3205 / \mathrm{psm} 000089$.

[4] A. Kingston, L. Robinson, H. Booth, M. Knapp, and C. Jagger, "MODEM project. Projections of multi-morbidity in the older population in England to 2035: estimates from the Population Ageing and Care Simulation (PACSim) model," Age and Ageing, vol. 47, no. 3, pp. 374-80, 2018, doi: 10.1093/ageing/afx201.

[5] K. Barnett, SW. Mercer, M. Norbury, G. Watt, S. Wyke, and B. Guthrie, "Epidemiology of multimorbidity and implications for health care, research, and medical education: a cross-sectional study," The Lancet, vol. 8, no 9836, pp. 37-43, 2012, doi: 10.1016/S0140-6736(12)60240-2Get.

[6] N. Ahmed et al., "Impact of malnutrition on survival and healthcare utilization in Medicare beneficiaries with diabetes: a retrospective cohort analysis," BMJ Open Diabetes Research and Care, vol. 6, no. 1, pp. 1-9, Feb 2018, doi: 10.1136/bmjdrc-2017-000471.

[7] S. Musich et al., "The Impact of Obesity on Health Care Utilization and Expenditures in a Medicare Supplement Population," Gerontology and Geriatric Medicine, vol. 2, pp. 1-9, 2016, doi: 10.1177/2333721415622004.

[8] CH. Gong, H. Kendig, X. He, "Factors predicting health services use among older people in China : An analysis of the China Health and Retirement Longitudinal Study 2013," BMC Health Services Research, vol. 16, no. 1, pp. 116, 2016, doi: 10.1186/s12913-016-1307-8.

[9] J. Häußler, "Effects of Obesity and Physical Activity on Health Care Utilization and Costs," pp.1-23, 2014, [Online]. Available: http://www.uni-konstanz.de/FuF/wiwi/workingpaperseries/WP_07_Haussler_2014.pdf.

[10] J. Strauss, F. Witoelar, and B. Sikosi, "IFLS5_User_Guide_Vol_1.," 2016, [Online]. Available: https://www.rand.org/content/dam/rand/pubs/working_papers/WR1100/WR1143z1/RAND_WR1143z1.pdf.

[11] MA. Khanam, PK. Streatfield, ZN. Kabir, C. Qiu, C. Cornelius, and A. Wahlin, "Prevalence and Patterns of Multimorbidity among Elderly People in Rural Bangladesh: A Cross-sectional Study," J Health Popul Nutr., vol. 29, no. 4 pp. 406-14, 2015, doi: 10.3329/jhpn.v29i4.8458

[12] H. Chen, M. Cheng, Y. Zhuang, and JB. Broad, "Multimorbidity among middle-aged and older persons in urban China: Prevalence, characteristics and health service utilization," Geriatrics and Gerontology International, vol. 18, no. 10, pp. 1447-52, Oct. 2018, doi: 10.1111/ggi.13510.

[13] B. A. Vargas et al., "Variations in healthcare access and utilization among Mexican immigrants: the role of documentation status," Journal of Immigrant and Minority Health, vol. 14, no. 1, pp. 146-155, 2012, doi: 10.1007/s10903-010-9406-9.

[14] T. Amente and B. Kebede, "Determinants of health service utilization among older adults in Bedele Town, illubabor zone, Ethiopia," J Diabetes Metab, vol. 7, no. 11, pp. 1-7, 2016, doi: 10.4172/2155-6156.1000713. 
[15] H. Kim and M. Lee, "Factors associated with health services utilization between the years 2010 and 2012 in Korea : using Andersen's Behavioral model," Osong Public Health and Research Perspectives, vol. 7, no. 1, pp. 18-25, 2016, doi: 10.1016/j.phrp.2015.11.007.

[16] P.A. Dalinjong et al., "The association between health insurance status and utilization of health services in rural Northern Ghana: evidence from the introduction of the National Health Insurance Scheme," Journal of Health, Population and Nutrition, vol. 36, no. 1, pp. 1-0, Dec. 2017, doi: 10.1186/s41043-017-0128-7.

[17] I. Stirbu, AE. Kunst, A. Mielck, and JP. MacKenbach, "Inequalities in utilisation of general practitioner and specialist services in 9 European countries," BMC Health Services Research, vol. 11, no. 288, pp. 1-8, 2011, doi: 10.1186/1472-6963-11-288.

[18] G. Gotsadze, A. Murphy, N. Shengelia, and A. Zoidze, "Healthcare utilization and expenditures for chronic and acute conditions in Georgia: Does benefit package design matter?," BMC Health Services Research, vol. 15, no. 88, pp. 1-10, 2015, doi: 10.1186/s12913-015-0755-x.

[19] N. Saquib et al., "Chronic disease prevalence among elderly Saudi men," International Journal of Health Sciences, vol. 11, no. 5, pp. 11-16, 2017.

[20] E. Vulcano, Y. Lee, T. Yamany, S. Lyman, and A. Della Valle, "Obese patients undergoing total knee arthroplasty have distinct preoperative characteristics: An insti- tutional study of 4718 patients," Journal of Arthroplasty, vol. 28, no. 7, pp. 1125-9, 2013, doi: 10.1016/j.arth.2012.10.028.

[21] NG. Onyeneho, U. V. Amazigo, NA. Njepuome, OC. Nwaorgu, and JC. Okeibunor, "Perception and utilization of public health services in Southeast Nigeria: Implication for health care in communities with different degrees of urbanization," International Journal for Equity in Health, vol. 15, no. 12, pp. 1-11, 2016, doi: 10.1186/s12939-0160294-z.

[22] E. Madyaningrum, C. Ying-Chih, and C. Kun-Yang, "Factors associated with the use of outpatient services among the elderly in Indonesia," BMC Health Services Research, vol. 18, no. 1, pp. 1-9, 2018, doi: 10.1186/s12913-018$3512-0$

[23] K. Vals, R. Kiivet, and M. Leinsalu, "Alcohol consumption, smoking and overweight as a burden for health care services utilization : a cross-sectional study in Estonia," BMC Health Services Research, vol. 13, no. 772, pp. 1-9, 2013, doi: 10.1186/1471-2458-13-772.

[24] G. Egger and J. Dixon, "Beyond obesity and lifestyle: a review of 21 st century chronic disease determinants," BioMed Research International, vol. 2014, pp. 1-12, Oct. 2014, doi: 10.1155/2014/731685.

[25] WB. Stephenson, "The Experiences of Obese African American Women and Their Utilization of Preventive Healthcare Services," Dissertation, Georgia State University, 2011.

[26] N. Sundresh and RV. Nagmothe, "A Study of Determinant of Long Waiting Period in Outpatient Department and Recommendation on reducing waiting time in a Superspecialty Hospital," Journal of Medical Science And clinical Research, vol. 5, no. 12, pp. 31491-9, 2017, doi: 10.18535/jmscr/v5i12.43.

[27] Y. Terfa, G. Germossa, F. Hailu, G. Feyisa, and F. Jeleta, "Determinants of health care utilization among the elderly population in Jimma Town, Oromia Region, Southwest Ethiopia," Int Arch Nurs Health Care, vol. 5, no. 3, pp. 1-6, 2019, doi: 10.23937/2469-5823/1510131.

[28] X. Zhang, B. Yu, T. He, P. Wang, "Status and determinants of health services utilization among elderly migrants in China," Global Health Research and Policy, vol. 3, no. 1, pp. 1-10, 2018, doi: 1186/s41256-018-0064-0.

[29] S. Sanjel, N. Mudbhari, A. Risal, and K. Khanal, "The utilization of health care services and their determinants among the elderly population of Dhulikhel Municipality," Kathmandu University Medical Journal, vol. 10, no. 37 , pp. 34-9, 2012, doi: 10.3126/kumj.v10i1.6911.

[30] E. Lahana, E. Pappa, D. Niakas, "Do place of residence and ethnicity affect health services utilization? Evidence from Greece," International Journal for Equity in Health, vol. 10, no. 1, pp. 1-9, Dec 2011, doi: 10.1186/14759276-10-16. 